\title{
Nur77 promotes cigarette smoke-induced autophagic cell death by increasing the dissociation of Bcl2 from Beclin-1
}

\author{
HUIPING QIN $^{1}$, FENG GAO ${ }^{2}$, YANNI WANG ${ }^{1}$, BIN HUANG $^{2}$, LING PENG ${ }^{1}$, \\ BIWEN $\mathrm{MO}^{3}$ and CHANGMING WANG ${ }^{2}$
}

\author{
${ }^{1}$ Department of Respiratory Medicine (Department of Respiratory and Critical Care Medicine), \\ Key Site of The National Clinical Research Center for Respiratory Disease, Xiangya Hospital, Central South University, \\ Changsha, Hunan 410008; ${ }^{2}$ Department of Respiratory Medicine, The Fifth Affiliated Hospital of Guilin \\ Medical University, Guilin, Guangxi 541002; ${ }^{3}$ Department of Respiratory Medicine, \\ Guilin Medical University, Guilin, Guangxi 541001, P.R. China
}

Received November 15, 2018; Accepted April 8, 2019

DOI: $10.3892 /$ ijmm.2019.4184

\begin{abstract}
Chronic obstructive pulmonary disease (COPD) is characterized by partially reversible airflow limitation and persistent alveolar destruction, and autophagy is involved in the pathogenesis of cigarette smoke (CS)-induced COPD. Nuclear receptor 77 (Nur77) participates in a number of biological processes, including apoptosis, autophagy and in disease pathogenesis; however, the role of Nur77 in COPD remains unknown. Thus, in this study, we aimed to elucidate the role of Nur77 in COPD. We report that CS promotes Nur77 expression and nuclear export in vivo and in vitro, which increases cigarette smoke extract (CSE)-induced autophagy. In addition, we found that lung tissues, human bronchial epithelial (HBE) cells and A549 cells exposed to CS or CSE expressed lower levels of LC3 and Beclin-1 and contained fewer autophagosomes following Nur77 knockdown with siRNA-Nur77. Moreover, a co-immunoprecipitation assay demonstrated that CSE promoted autophagy, partly by accelerating the interaction between Nur77 and Bcl2, in turn leading to the increased dissociation of Bcl2 from Beclin-1; by contrast, leptomycin B (LMB) suppressed the dissociation of Bcl2 from Beclin-1. Taken together, the findings of this study demonstrate that Nur77 is involved in the CSE-induced
\end{abstract}

Correspondence to: Dr Changming Wang, Department of Respiratory Medicine, The Fifth Affiliated Hospital of Guilin Medical University, 12 Wenming Road, Guilin, Guangxi 541002, P.R. China

E-mail: 446268863@qq.com

Abbreviations: Nur77, nuclear receptor 77; CS, cigarette smoke; CSE, cigarette smoke extract; COPD, chronic obstructive pulmonary disease; RA, room air; LMB, leptomycin B; RAPA, rapamycin; 3-MA, 3-methyladenine; siRNA, small interfering RNA; HBE cells, human bronchial epithelial cells

Key words: nuclear receptor 77, autophagy, chronic obstructive pulmonary disease, Bcl2, Beclin-1 autophagic death of lung cells, and that this process is partially dependent on the increased interaction between Nur77 and $\mathrm{Bcl} 2$, and on the dissociation of Bcl2 from Beclin-1. This study illustrates the role of Nur77 in bronchial and alveolar destruction following exposure to $\mathrm{CS}$.

\section{Introduction}

Chronic obstructive pulmonary disease (COPD) includes chronic bronchitis and emphysema. COPD is the third leading cause of mortality worldwide, and is characterized by partially reversible airflow limitation and persistent alveolar destruction (1). The increasing morbidity and mortality of this disease increases the associated burdens on society (1). Exposure to first- and second-hand cigarette smoke (CS) is the most important risk factor for $\operatorname{COPD}(2,3)$. The percentage of elderly smokers who suffer from COPD is almost $50 \%(4,5)$. CS damages bronchial and alveolar epithelial cells by inducing cell death (6). However, the molecular mechanisms through which CS induces COPD remain incompletely understood.

Nuclear receptor 77 (Nur77), also known as NR4A1, TR3 or NGFI-B, belongs to the NR4A receptor subfamily which consists of Nurr1 (NR4A2, NOT) and NOR-1 (NR4A3, MINOR); Nur77 is also considered an orphan receptor as it lacks identified ligands (7-9). Similar to other nuclear receptors, Nur77 contains an activation function (AF)-1 N-terminal transactivation domain, a central zinc finger DNA-binding domain and an AF-2 C-terminal segment containing the ligand-binding domain (LBD) (7-9). In general, Nur77 resides in the cell nucleus, although some stimulants trigger Nur77 nuclear export (9). Nur77 plays a critical role in inflammation and in cellular processes, such as proliferation, differentiation, survival and death (9). Previous researchers investigating Nur77 have focused mostly on neurological disorders, cardiovascular diseases and cancer (10). Nur77 expression has been described in lung tissue and lung epithelial cells. Notably, Nur77 is overexpressed in the majority of lung cancer and pulmonary artery smooth muscle cell (PASMC) proliferation models (11). Nur77 has been shown to exert anti-inflammatory 
effects on ovalbumin (OVA)-induced airway allergic inflammation and in a lipopolysaccharide (LPS)-induced sepsis mouse model $(12,13)$. However, the role of Nur77 in cigarette smoke extract (CSE)-induced COPD remains unclear.

Autophagy is a cellular lysosomal degradation process that eliminates damaged organelles or aberrant proteins and is characterized by the activity of bilayer structures called autophagosomes $(14,15)$. Emerging evidence suggests that autophagy plays a deleterious role in CS-induced COPD $(14,16)$. The dysregulation of autophagy is responsible for CS-induced airway epithelial damage, such as the shortening of the cilia and the hyperproduction of mucus $(17,18)$. To a certain extent, CS-induced emphysema is due to an imbalance in autophagy. Recently, researchers have shown interest in the association between Nur77 and autophagy (19). It has been shown that when cells are treated with 1-(3,4,5-trihydroxyphenyl) THPN, a Nur77-targeting compound, Nur77 targets the mitochondria through contact with the outer membrane protein, Nix, and enters the mitochondria, in turn contributing to the dissipation of the mitochondrial membrane potential and to the induction of autophagy (19). Nur77 has been shown to promote the autophagy of PC12 cells, resulting in PC12 cell death (20). In addition, the interaction between Nur77 and Bcl2 has been shown to induce apoptosis in various types of cancer $(21,22)$. A recent study revealed that Nur77 binds to Bcl 2 family proteins (Bcl-B) and subsequently mediates autophagy, suggesting that the interaction between Bcl-B and Nur77 affects the stability of the Bcl-B-Beclin-1 complex and triggers autophagy (23). Bcl2 family proteins inhibit autophagy by binding to Beclin-1, as well as Bcl2 $(24,25)$. However, whether Nur77-Bcl2 complexes dissociate Beclin-1 from Bcl2 and subsequently induce autophagy remains unknown, particularly in the context of CS-induced autophagy.

Increasing evidence indicates that autophagy is critically involved in the pathogenesis of CS-induced COPD. Given the roles of Nur77 in autophagy, in this study, we aimed to determine whether CS triggers Nur77-induced autophagy and to elucidate the underlying mechanisms. We report that CS-induced autophagy requires the nuclear export of Nur77, the interaction between Nur77 and Bcl-2, and the dissociation of Beclin-1 from Bcl2.

\section{Materials and methods}

Animals. Male C57BL/6 mice (28 mice in total, 26-30 days old, weighing 11-14 g) were purchased from the Changsha SLAC Experimental Animal Center (Changsha, China). All mice were given water and food ad libitum under a 12/12-h light-dark cycle under specific pathogen-free conditions, and were bred to 10-12 weeks for establishing our model. All in vivo experiments were approved by the local Animal Health Service, the Central South University Animal Care Committee and were performed according to the National Institutes of Health guidelines on animal care and welfare.

Exposure to CS. The mice (28 mice were randomly divided into 4 groups, $\mathrm{n}=7$ per group, 4 groups in total, 10-12 weeks old) were exposed to air or CS, as previously described (26). Briefly, the whole bodies of the mice were exposed to CS from 8 cigarettes simultaneously (without a filter; Baisha, Changsha,
China) in a box $(40 \times 60 \times 50 \mathrm{~cm}), 4$ times for $25 \mathrm{~min}$ each at 20-min intervals; exposure to CS was carried out 5 days per week for 10 weeks. Baisha Pai cigarettes contain $10 \mathrm{mg}$ of tar, $1.0 \mathrm{mg}$ of nicotine and $13 \mathrm{mg}$ of carbon monoxide (CO). The animals in the control group were exposed to room air (RA). All animals received siRNA-Nur77-lentivirus (siRNA-Nur77 sequence, 5'-CGCCTGGCATACCGATCTAAA-3') or lentiviral vector vehicle (50 $\mu \mathrm{l}$ containing $1 \times 10^{9} /$ mouse/treatment) on the first day of each week.

Histopathological analysis and immunohistochemistry (IHC). The mice were anesthetized by an intraperitoneal injection of pentobarbital $(40 \mathrm{mg} / \mathrm{kg})$ at $24 \mathrm{~h}$ after the final CS exposure. One main bronchus was ligated, and the lung was perfused with $4 \%$ paraformaldehyde at a constant pressure of $2.45 \mathrm{kPa}$ for $1 \mathrm{~h}$ before being removed from the animal and then was placed into fresh $4 \%$ paraformaldehyde for $24 \mathrm{~h}$. The fixed lungs were embedded in paraffin and then were cut into $4-\mu \mathrm{m}$-thick lung tissues slices. Some lung slices were dewaxed with xylene, hydrated with ethanol and then stained with $20 \%$ hematoxylin for $5 \mathrm{~min}$ and $0.5 \%$ eosin for $3 \mathrm{~min}$ at room temperature (H\&E, G1120, Solarbio Science \& Technology, Beijing, China) for the analysis of inflammation and emphysema. A total of 10 of random fields were examined using a Leica digital microscope (Leica DM6B1 Leica, Wetzlar, Germany). Histopathology was graded by experienced pathologists using a semi-quantitative histology score system (27). Nur77 expression in lung tissues was detected by IHC according to a previously described protocol (12). Briefly, the lung tissues slices were incubated with an anti-Nur77 antibody (1:400; NB100-56745; Novus Biologicals, Centennial, CO, USA) overnight at $4{ }^{\circ} \mathrm{C}$, incubated with anti-rabbit $\operatorname{IgG}(\mathrm{ZB} 2301,1: 1,000)$ for $30 \mathrm{~min}$ at room temperature, and then stained with 3,3'-diaminobenzidine (DAB, DA1010, Solarbio Science \& Technology) as the chromagen. Finially, the slides were counterstained with hematoxylin, dehydrated and mounted. In total, 10 random fields were examined using a Leica digital microscope.

Reagents and antibodies. Dulbecco's modified Eagle's medium (DMEM) and fetal bovine serum (FBS) were purchased from Gibco/Thermo Fisher Scientific (Waltham, MA, USA). Dulbecco's phosphate-buffered saline (DPBS) was purchased from Invitrogen/Thermo Fisher Scientific. In addition, 3-methyladenine (3-MA) and rapamycin (RAPA) were purchased from Selleck Chemicals (Shanghai, China), and leptomycin B (LMB) was purchased from the Beyotime Institute of Biotechnology (Shanghai, China). The anti-Nur77 antibody was purchased from Novus Biologicals, and anti-LC3 (cat. nos. 12741 and 2775) and anti-GAPDH antibodies (cat. no. 5174) were purchased from Cell Signaling Technology (Danvers, MA, USA). Anti-Beclin-1 (cat. no. ab210498) and anti-Bcl2 (cat. no. ab692) antibodies were purchased from Abcam (Cambridge, MA, USA). Anti-rabbit and mouse IgG (ZB2301, ZB2305, 1:2,000) were purchased from Zhong Shan Golden Bridge Biotechnology Co., Ltd. (Beijing, China).

Preparation of CSE. CSE was prepared using a smoke device as previously described (28). A filtered cigarette (Baisha Pai) was combusted with a vacuum pump (VWR International, West Chester, PA, USA), and the smoke was directed via a tube 
through $5 \mathrm{ml}$ of PBS. This solution, which was considered to be $100 \%$ CSE, was filtered through a $0.22-\mu \mathrm{m}$ pore filter (Lida Manufacturing Corp., Kenosha, WI, USA) for sterilization. Different preparations of CSE were standardized by measuring the absorbance at a wavelength of $320 \mathrm{~nm}$ using a NanoDrop 2000 spectrophotometer (Thermo Fisher Scientific). Freshly prepared CSE was diluted with culture medium supplemented with $10 \%$ FBS immediately prior to use and was used within $30 \mathrm{~min}$.

Cells and cell culture. Human bronchial epithelial (HBE) cells and A549 cells were kindly provided by the Central South University Advanced Research Center (Changsha, China) and maintained in DMEM supplemented with 10\% FBS, $100 \mathrm{U} / \mathrm{ml}$ penicillin and $100 \mathrm{mg} / \mathrm{ml}$ streptomycin in a humidified atmosphere containing $5 \% \mathrm{CO}_{2}$ at $37^{\circ} \mathrm{C}$. CSE and other reagents (rapamycin, 3-MA, LMB, siRNA) were added to the HBE or A549 cells at the indicated concentrations and for the indicated periods of time (see corresponding figure legends for details).

Cell transfection. siRNA-Nur77 (sequence, 5'-TCGAGGACT TCCAGGTGTA-3') and a negative control sequence (cat. no. siN05815) were obtained from RiboBio (riboFect ${ }^{\mathrm{TM}} \mathrm{CP}$; Guangzhou, China). The cells in the exponential growth phase were seeded in 6-well plates at $4 \times 10^{5}$ cells per well, grown to $40-50 \%$ density for $24 \mathrm{~h}$, and transfected with siRNA-Nur77 or negative control for a further $36 \mathrm{~h}$ according to the manufacturer's recommended protocol. siRNA-Nur77, pre-mixed with riboFECT ${ }^{\mathrm{TM}} \mathrm{CP}$ buffer and riboFECT ${ }^{\mathrm{TM}} \mathrm{CP}$ reagent, was added to the medium at a final concentration of $100 \mathrm{nM}$. Western blot analysis was performed to evaluate the transfection efficiency.

Cell proliferation assay. The inhibition ratio of CSE was measured with a Cell Counting kit-8 (CCK-8; Dojindo, Kumamoto, Japan) assay, as specified. A total of $1 \times 10^{4} \mathrm{HBE}$ cells or $5 \times 10^{3}$ A549 cells were seeded into 96-well plates, grown to nearly $40 \%$ confluence and transfected with siRNA or negative control for $36 \mathrm{~h}$. Subsequently, the cells were treated with or without rapamycin $(1 \mathrm{mM})$ or 3-MA $(2.5 \mathrm{mM})$ or left untreated for $2 \mathrm{~h}$ and then exposed to 5\% CSE for a further $24 \mathrm{~h}$. After all the treatments were performed, $10 \mu \mathrm{l}$ of CCK- 8 were added to each well for $1 \mathrm{~h}$ at $37^{\circ} \mathrm{C}$, and the absorbance was detected at $450 \mathrm{~nm}$ with a microplate reader (BioTek Instruments, Winooski, VT, USA).

Immunofluorescence. A total of $1 \times 10^{5} \mathrm{HBE}$ cells or $5 \times 10^{4}$ A549 cells were seeded in 6-well glass-bottom dishes and subjected to various treatments for the indicated periods of time. The treated cells were washed and fixed in $4 \%$ paraformaldehyde for $20 \mathrm{~min}$, treated with TritonX-100 for $15 \mathrm{~min}$, and blocked with $5 \%$ bovine serum albumin (BSA) for $30 \mathrm{~min}$. The cells were then incubated with primary antibodies (anti-Nur77, 1:200; anti-Bcl2, 1:200; anti-LC3, 1:200) overnight at $4^{\circ} \mathrm{C}$, washed with PBS, and then incubated with fluorescent secondary antibodies (anti-rabbit IgG: 711-025-152, anti-mouse IgG: 715-545-150; 1:200 dilution; Jackson ImmunoResearch Laboratories, Inc., West Grove, PA, USA) for $1 \mathrm{~h}$ at $37^{\circ} \mathrm{C}$; after washing with PBS, and the cells were stained with DAPI (C1005, Beyotime Institute of Biotechnology, Haimen, China) for $5 \mathrm{~min}$ at room temperature.
Following washing with PBS, the coverslips were sealed by anti-fade mounting Medium (P0126-5 ml, Beyotime Institute of Biotechnology). Images were captured under a fluorescence microscope (Leica, Buffalo Grove, IL, USA).

Western blot analysis. Total proteins were extracted with radioimmunoprecipitation assay (RIPA) lysis buffer (Beyotime Institute of Biotechnology) and quantified with the bicinchoninic acid (BCA) method to ensure equal concentration. Loading buffer and total proteins were mixed and heated at $95^{\circ} \mathrm{C}$ for $10 \mathrm{~min}$ to denature albumin. Equal quantities of the samples $(30-50 \mu \mathrm{g} /$ well) were separated by sodium dodecyl sulfate-polyacrylamide gel electrophoresis (SDS-PAGE, $10-15 \%)$ and transferred to polyvinylidene fluoride (PVDF) membranes (Millipore, Billerica, MA, USA). After blocking with $5 \%$ non-fat milk, the membranes were incubated with corresponding primary antibodies (anti-Nur77, 1:1,000; anti-LC3, 1:1,000; anti-Beclin-1, 1:1,000; anti-GAPDH, $1: 1,000)$ at $4^{\circ} \mathrm{C}$ overnight. Subsequently, the membranes were incubated with secondary antibodies (anti-rabbit IgG: 1:2,000) for a further $1 \mathrm{~h}$ at $37^{\circ} \mathrm{C}$, and the proteins were detected with an enhanced chemiluminescence (ECL) reagent (Millipore) and an ECL system (Syngene, Cambridge, England, UK). Image J 1.48v software (National Institutes of Health) was used to measure the gray value of each band.

Transmission electron microscopy (TEM). The HBE and A549 cells were collected and fixed with $2.5 \%$ glutaradehyde overnight at at $4^{\circ} \mathrm{C}$; they were then washed, and fixed with $1 \%$ osmium tetroxide for $1 \mathrm{~h}$. Subsequently, the cells were dehydrated with a graded ethanol series, and embedded in epoxy resin (CAS 25068-38-6; Santa Cruz Biotechnology, Santa Cruz, CA, USA). Ultrathin sections were detected using a transmission electron microscope (Hitachi Ltd., Tokyo, Japan).

Co-immunoprecipitation. The HBE cells were treated with LMB $(10 \mathrm{ng} / \mathrm{ml})$ for $2 \mathrm{~h}$ or left untreated, and were then exposed to 5\% CSE for a further $24 \mathrm{~h}$. The cells were collected, lysed in immunoprecipitation (IP)-RIPA lysis buffer, and then centrifuged at $10,000 \mathrm{x} \mathrm{g}$ for $10 \mathrm{~min}$ at $4^{\circ} \mathrm{C}$. The supernatants were collected and quantified with the BCA method to ensure equal concentration; $10 \%$ and another $3 \%$ of total proteins were used as input experiments. The remaining were incubated with anti-Nur77 (1:50), anti-Bcl2 (1:20), or anti-Beclin-1 (1:30) antibodies or with the same species IgG (anti-GAPDH rabbit antibodies, cat. no. 5174; and anti-GAPDH mouse antibodies, cat. no. 51332; 1:20 dilution; Cell Signaling Technology) as a negative control overnight at $4^{\circ} \mathrm{C}$. Protein $\mathrm{G}$ agarose beads were pre-washed 3 times in IP-RIPA lysis buffer and then incubated with the protein/antibody mixtures at $4^{\circ} \mathrm{C}$ for $4 \mathrm{~h}$ on shaking tables. The supernatant was discarded and the precipitate was retained and washed 4 times with IP-RIPA lysis buffer. Loading buffer was added to the precipitate; and the mixture was then heated at $95^{\circ} \mathrm{C}$ for $5 \mathrm{~min}$. After the beads were discarded, the supernatant was analyzed by western blot analysis.

Statistical analysis. The data are expressed as the means \pm standard error of the mean (SEM). The data were analyzed using one-way analysis of variance (ANOVA) followed by Bonferroni's multiple comparison tests with GraphPad Prism 5.0 software 
(GraphPad Software, San Diego, CA, USA). Differences with P-values $<0.05$ were regarded as statistically significant.

\section{Results}

Nur77 is overexpressed in lung tissues and pulmonary cells following exposure to CS and CSE administration. Nur77, which plays a critical role in inflammation and in cell proliferation, survival and death, is overexpressed in the majority of lung cancer and PASMC proliferation models (11). However, limited information of the mechanisms through which CS affects the expression of Nur77 is available. Thus, in this study, in order to shed light into this matter, C57BL/6 mice were bred to 10-12 weeks and were randomly divided into 4 groups, and the weight growth of each group did not differ significantly (compared to weight at purchase, data not shown). The C57BL/6 mice were exposed to RA or CS for 10 weeks, and lung tissues were collected the day after the final CS exposure. We found that exposure to CS significantly decreased the weight gain of the mice; however, lentivirus infection did not (Fig. 1B, compared to initial weight: Weight of 26-30-day-old mice, 11-14 g). Nur77 expression in the lung tissues was examined by immunohistochemical staining and western blot analysis. The number of Nur77-positive pulmonary epithelial cells in the CS-exposed group was higher than that in the RA group (Fig. 1A and C). Western blot analysis confirmed that CS increased the Nur77 levels in the lung tissues (Fig. 1D and E). We also examined the effects of various concentrations of CSE on Nur77 expression at the cellular level. The Nur77 levels significantly increased with the increasing CSE concentrations, and the group of HBE cells treated with 5\% CSE, expressed higher Nur77-levels than the other groups (Fig. 1F and G). To further confirm the upregulation of Nur77 by CSE, we also examined the Nur77 levels in A549 cells exposed to various concentrations of CSE. Consistent with our findings with the HBE cells, the Nur77 levels were elevated with the increasing CSE concentrations (Fig. 1H and I). These results demonstrated that CS and CSE increased the Nur77 levels in pulmonary epithelial cells.

Knockdown of Nur77 attenuates CS-induced lung injury and CSE-induced cell death. Exposure to CS results in pulmonary epithelial cell dysfunction and eventual cell death. Lung tissues and pulmonary epithelial cells treated with CS and CSE overexpressed Nur77; however, whether the high Nur77 levels participate in the pathophysiological processes of pulmonary epithelial cell dysfunction and cell death remained unclear. The results of this study revealed that CS-exposed mice exhibited more severe destruction of the pulmonary alveoli and bronchial tubes than RA-exposed mice; however, intratracheal inoculation with siRNA-Nur77 lentivirus mitigated the observed CS-induced lung injury (Fig. 2A and B). We further found that CSE reduced the viability of the HBE and A549 cells, an effect that was attenuated by the knockdown of Nur77 (Fig. 2C and D).

Nur77 mediates CS-induced autophagy in vitro and in vivo. The autophagy of lung epithelial cells is involved in the pathological process of CS-induced COPD. In this study, combined treatment with CSE and RAPA (an autophagy activator) accelerated cell death, while 3-MA (an autophagy inhibitor) effectively attenuated CSE-induced cell death (Fig. 3A). It has been demonstrated that Nur77 mediates autophagic cell death in mammalian cells (29). Hence, we hypothesized that Nur77 may be involved in CSE-induced autophagy. To investigate the role of Nur77 in CSE-induced autophagy, the HBE cells were treated with 5\% CSE for $24 \mathrm{~h}$, and the expression levels of LC3 (an autophagy marker; an increasing LC3II/LC3I ratio indicates autophagy induction) and Beclin-1 (responsible for autophagy initiation) were then examined. We found that the LC3I to LC3II conversion and Beclin-1 expression increased synchronously with Nur77 upregulation (Fig. 3B-D). siRNA-Nur77 inhibited the expression of Nur77 (Fig. 3B), and the knockdown of Nur77 with siRNA-Nur77 attenuated the ability of CSE to upregulate LC3II/LC3I and Beclin-1 expression (Fig. 3B-D). These data indicate that the CSE-induced upregulation of Nur77 is linked to CSE-induced autophagy. A similar result was observed in the A549 cells co-treated with siRNA-Nur77 and CSE (Fig. 3E-G). Moreover, we found that punctate LC3 staining was greater in the CSE-treated HBE and A549 cells than in the control cells, as indicated by immunofluorescence staining, while transfection with siRNA-Nur77 diminished punctate LC3 staining, and the conversion of LC3-I to LC3-II (Fig. 3H and I).

To determine whether Nur77 plays a key role in CS-induced autophagy in vivo, mice were exposed to CS and treated with siRNA-Nur77 lentivirus for 10 weeks, and LC3, and Beclin-1 protein levels were detected in the lung tissues by western blot analysis. The lung tissues from the group of mice co-treated with siRNA-Nur77 lentivirus and CS demonstrated lower levels of LC3I to LC3II conversion and a lower Beclin-1 protein expression than those from the group exposed to CS only, indicating that autophagy was inhibited (Fig. 4).

Knockdown of Nur77 decreases CSE-induced autophagosome formation at the ultrastructural level. To confirm that autophagy is indeed induced by CSE, the HBE and A549 cells treated with 5\% CSE were analyzed by TEM for the evidence of autophagy (Fig. 5). A greater abundance of double-membrane structures containing organelles and more mature autophagosomes containing electron-dense regions were evident in the CSE-exposed HBE cells than in the control cells (Fig. 5A). Similar to the HBE cells, the CSE-exposed A549 cells exhibited much more autophagic features compared to those of the untreated group (Fig. 5B). We then examined whether Nur77 is involved in morphological changes consistent with autophagy. The presence of autophagic structures was markedly reduced in the CSE-exposed HBE and A549 cells following transfection with siRNA-Nur77 (Fig. 5). This finding supports our hypothesis that CSE-induced Nur77 upregulation is responsible for CSE-induced autophagy.

The interaction between Nur77 and Bcl2 is enhanced by CSE. $\mathrm{Bcl}-2$ family proteins are key regulators of programmed cell death. It has been previously clarified that Nur77 interacts with $\mathrm{Bcl} 2$ and can convert the function of $\mathrm{Bcl} 2$ from a protective function to a pro-death function; in addition, some stimuli can regulate the interaction of Nur77 and Bcl2 to induce cell apoptosis (30). The Nur77-Bcl2 complex also induces autophagy (30). In this study, we observed the Nur77 transfer to the cytoplasm in CSE-exposed HBE cells, while LMB 
A

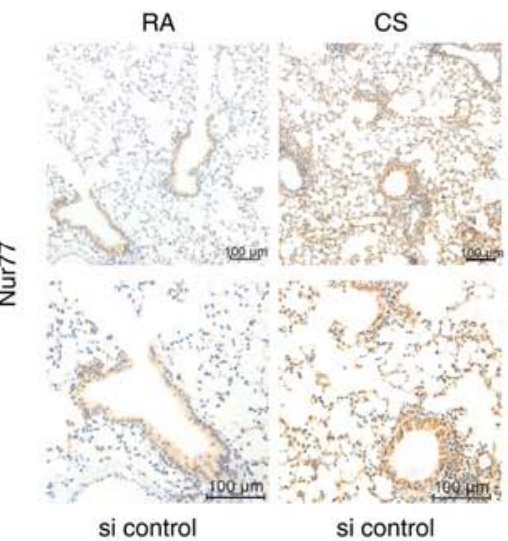

si control si control
RA

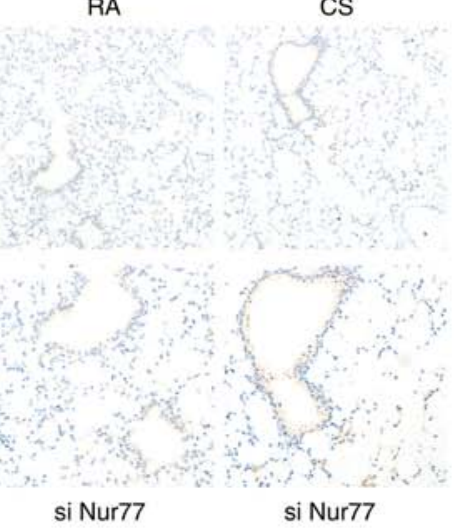

si Nur77

si Nur77

D

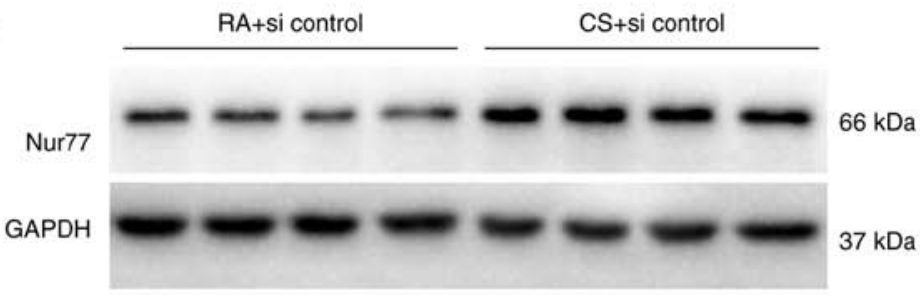

F

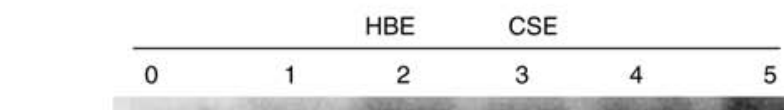

Nur77

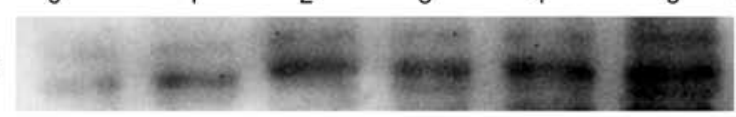

GAPDH

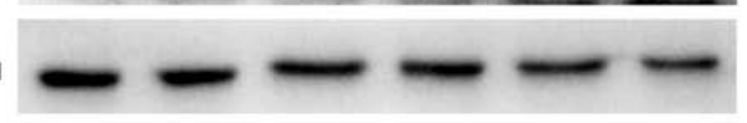

$\mathrm{H}$

\begin{tabular}{rrrrrr}
\multicolumn{7}{c}{ A549 } & CSE & \\
\hline 0 & 1 & 2 & 3 & 4 & 5
\end{tabular}

(\%)

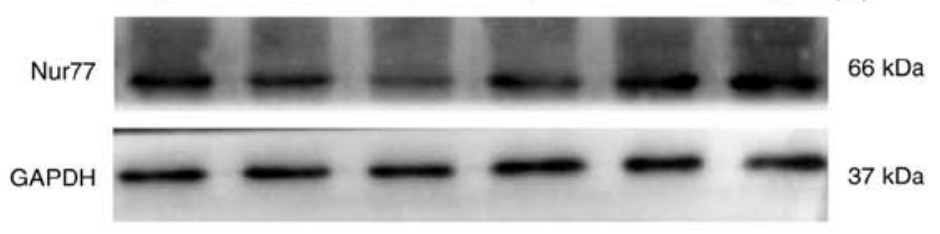

(\%)

$\mathrm{B}$
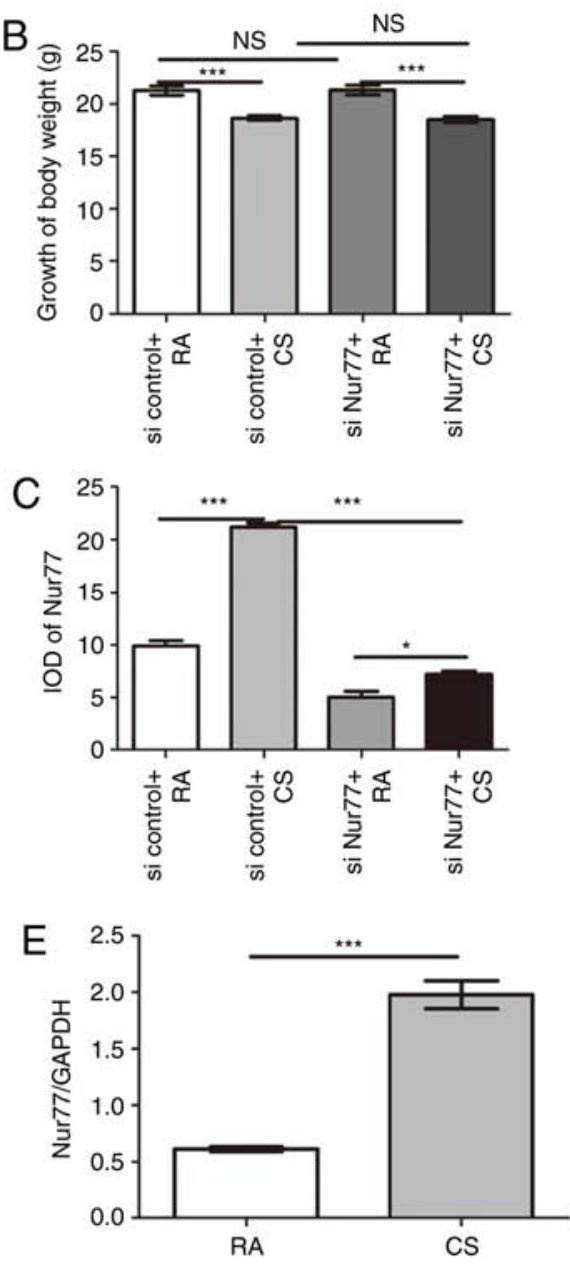

$66 \mathrm{kDa}$

$37 \mathrm{kDa}$
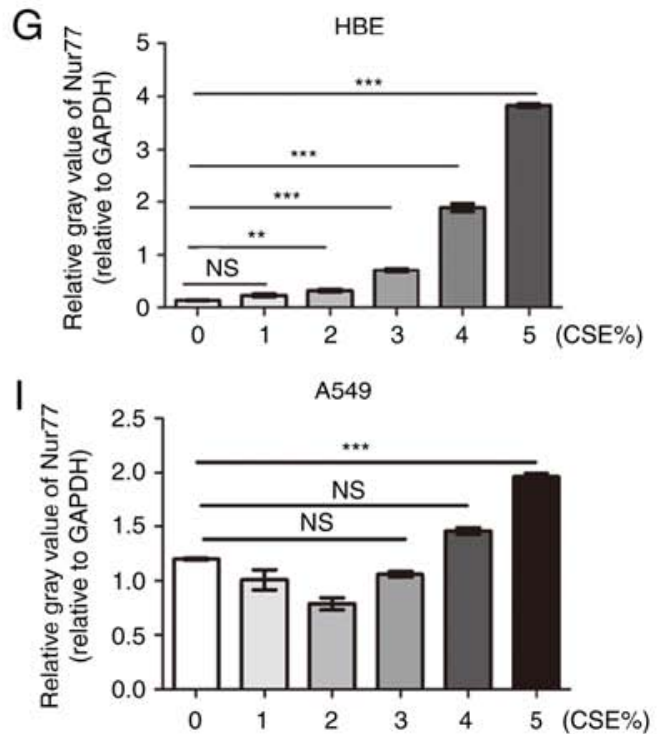

Figure 1. CS exposure promotes the upregulation of Nur77 in vivo and in vitro. (A and C-E) Mice were infected with siRNA-Nur77-lentivirus or lentiviral vector vehicle and exposed to CS or RA for 10 weeks, and the expression of Nur77 was examined by immunohistochemical staining and western blot analysis. The quantification of Nur77 staining though integrated optical density (IOD). Scale bars, $100 \mu \mathrm{m}$. (B) CS affected the weight gain of the mice. (F-I) HBE and A549 cells were exposed to various concentrations of CSE for $24 \mathrm{~h}$. Western blot analysis was performed to analyze the Nur77 levels. ${ }^{*} \mathrm{P}<0.05,{ }^{* *} \mathrm{P}<0.01$ and ${ }^{* * *} \mathrm{P}<0.001$; ns, not significant. Each experiment was repeated at least 3 times. CS, cigarette smoke; RA, room air; Nur77, nuclear receptor 77; HBE cells, human bronchial epithelial cells.

prevented the CSE-induced Nur77 nuclear export (Fig. 6A). To clarify whether CSE promotes the interaction between Nur77 and Bcl2, double immunofluorescence was first used to examine whether Nur77 co-localizes with Bcl2 in the cyto- plasm of HBE cells that were exposed or not to CSE. When the HBE cells were exposed to CSE, Nur77 and Bcl2 co-localized in the cytoplasm, while in the control cells, Nur77 existed mainly in the nucleus, and Bcl2 was distributed in the nucleus 
A
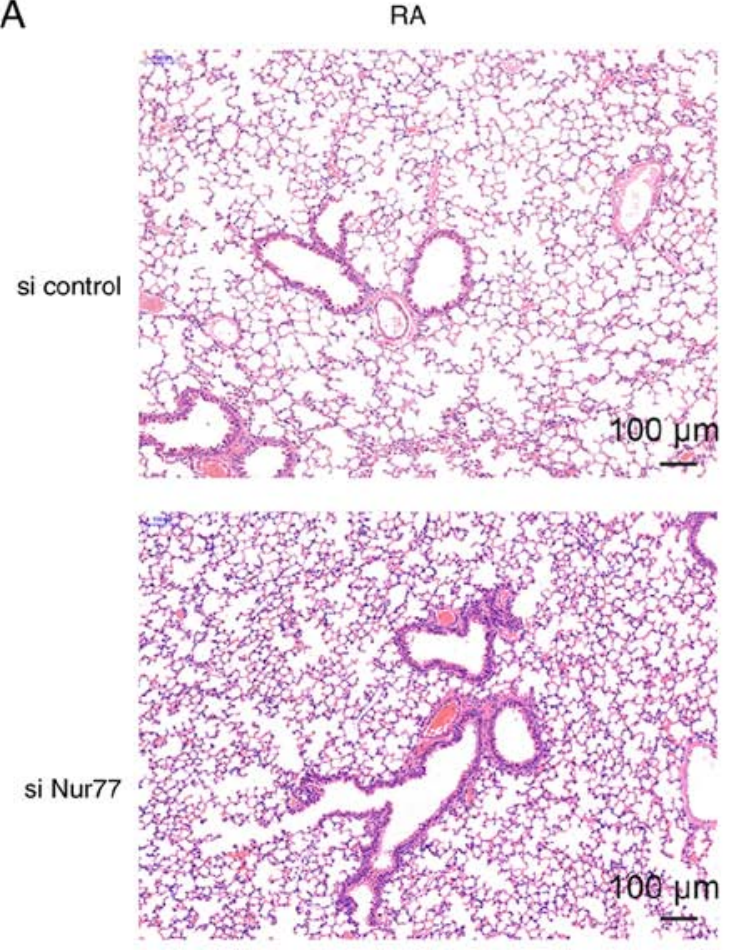

B

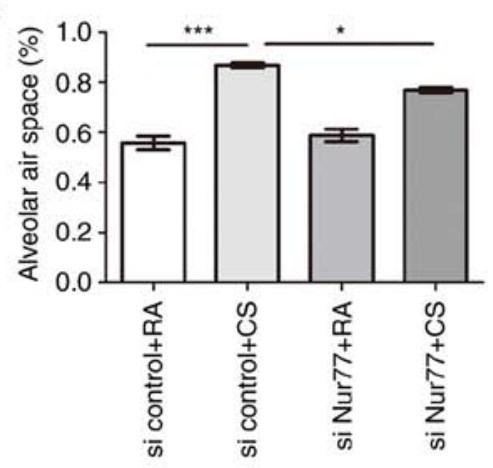

C

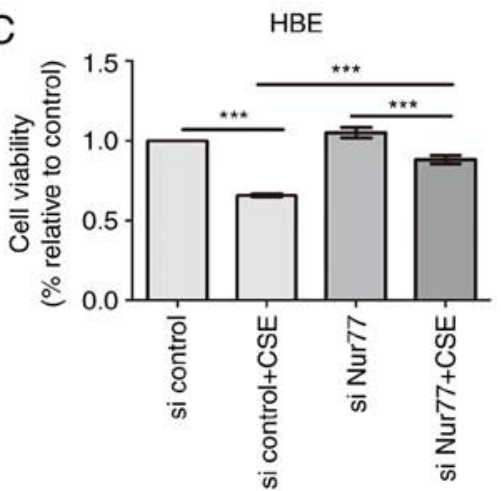

CS
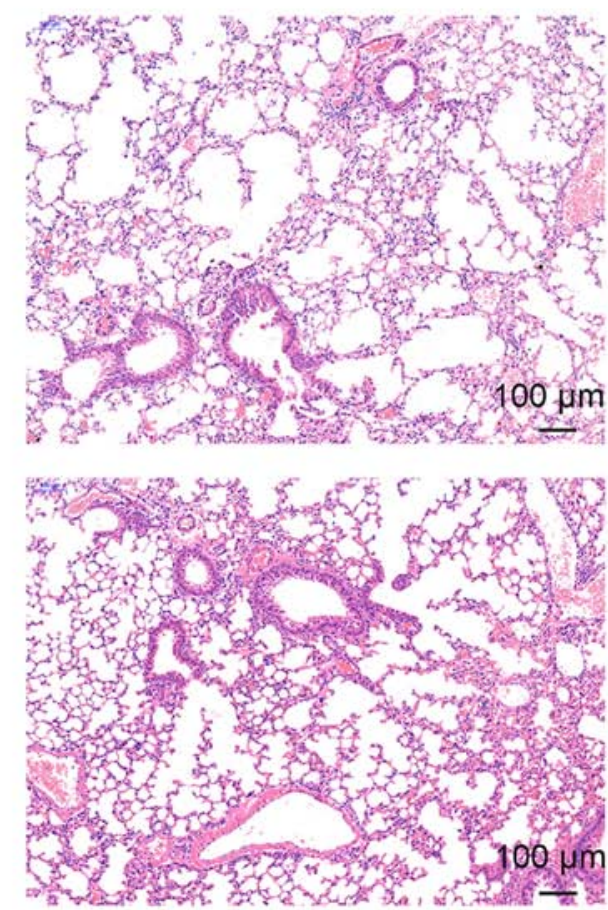

Figure 2. Nur77 inhibits CS-induced lung destruction and cell death. (A and B) Mice were treated as described in the Materials and methods. H\&E staining was used to observe lung morphology; scale bars, $100 \mu \mathrm{m}$. (C) HBE cells were transfected with siRNA-Nur77 or control siRNA for $36 \mathrm{~h}$ and then treated with $5 \%$ CSE for $24 \mathrm{~h}$. Cell proliferation was detected by CCK-8 assay. (D) A549 cells were transfected with siRNA-Nur77 or control siRNA for $36 \mathrm{~h}$ and then treated with 5\% CSE for $24 \mathrm{~h}$. Cell proliferation was detected by CCK-8. ${ }^{*} \mathrm{P}<0.05^{* *} \mathrm{P}<0.01$ and ${ }^{* * *} \mathrm{P}<0.001$. Each experiment was repeated at least 3 times. CS, cigarette smoke; RA, room air; Nur77, nuclear receptor 77; HBE cells, human bronchial epithelial cells.

and cytoplasm (Fig. 6B). Subsequently, we investigated whether the interaction between Nur77 and $\mathrm{Bcl} 2$ was enhanced in CSE-exposed cells with a co-immunoprecipitation assay. In the absence CSE, only endogenous Nur77 and a small amount of Bcl 2 were pulled down by an anti-Nur77 antibody. Upon CSE exposure, a greater amount of Nur77 co-immunoprecipitated with Bcl2 (Fig. 7A). The same outcome was detected when the cell lysates were immunoprecipitated with an anti-Bcl2 antibody (Fig. 7B). These results indicate that CSE promotes the interaction between Nur77 and Bcl2.

Nur77 plays a role in the CSE-induced dissociation of Bcl2 from Beclin-1. The autophagic function of Beclin-1 is inhibited by Bcl-2 and is induced when Bcl-2 dissociates from Beclin-1 (24,30). It has been verified that the interaction of Nur77 and Bcl 2 family proteins augments autophagy (30). The results of this study indicated thatCSE induced autophagy by the elevating Nur77 levels and increasing the interaction between Nur77 and Bcl2. To determine whether the CSE-induced increase in Nur77-Bcl-2 complexes increases dissociation of Beclin-1 from Bcl2, we then triggered Beclin-1-dependent autophagy. We first performed co-immunoprecipitation experiments with the HBE cells with or without CSE exposure to detect the endogenous levels of both $\mathrm{Bcl} 2$ and Beclin-1. We observed that an anti-Bcl2 antibody and an anti-Beclin-1 antibody pulled down both $\mathrm{Bcl} 2$ and Beclin-1 in the absence of CSE; in addition, smaller amounts of Bcl2 and Beclin-1 were pulled down following exposure to CSE (Fig. 8). We then sought to determine whether the binding of Nur77 to $\mathrm{Bcl} 2$ prompts the dissociation of the Bcl2-Beclin-1 complex in $\mathrm{HBE}$ cells exposed to CSE. LMB inhibits Nur77 nuclear export and then prevents Nur77 from interacting with $\mathrm{Bcl} 2$. HBE cells were thus treated with CSE in the presence or absence of LMB. Through co-immunoprecipitation assays, we discovered 
A

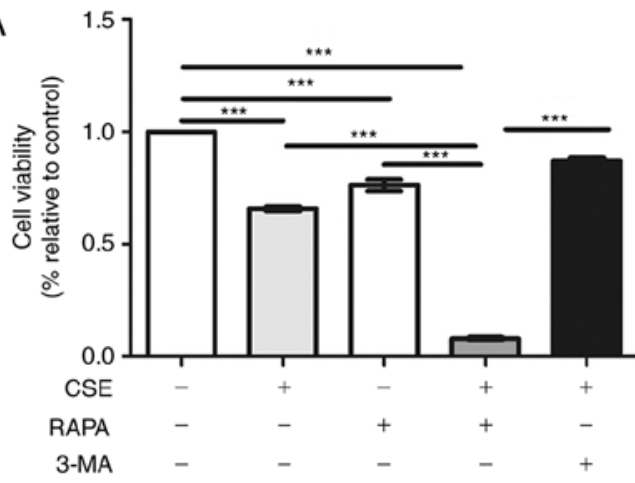

B

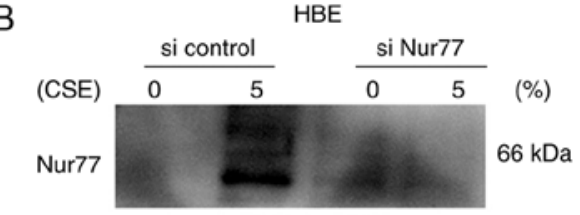

Beclin-1
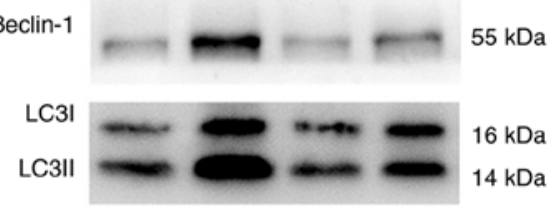

GAPDH

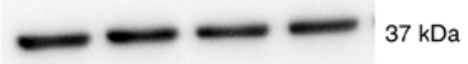

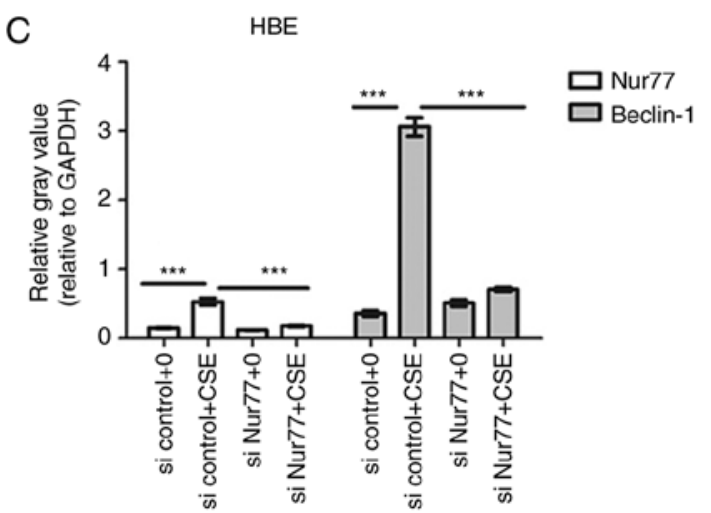

$\mathrm{D}$

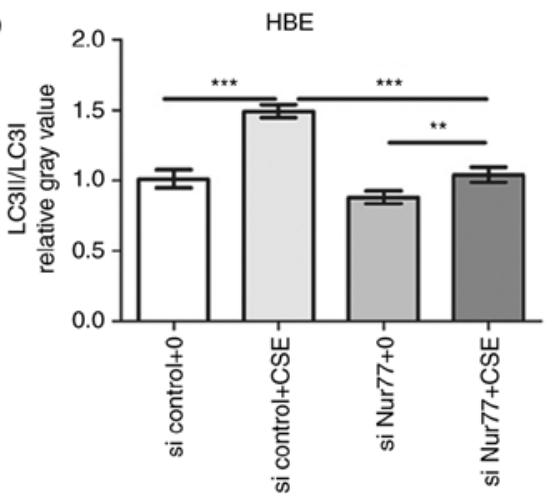

E
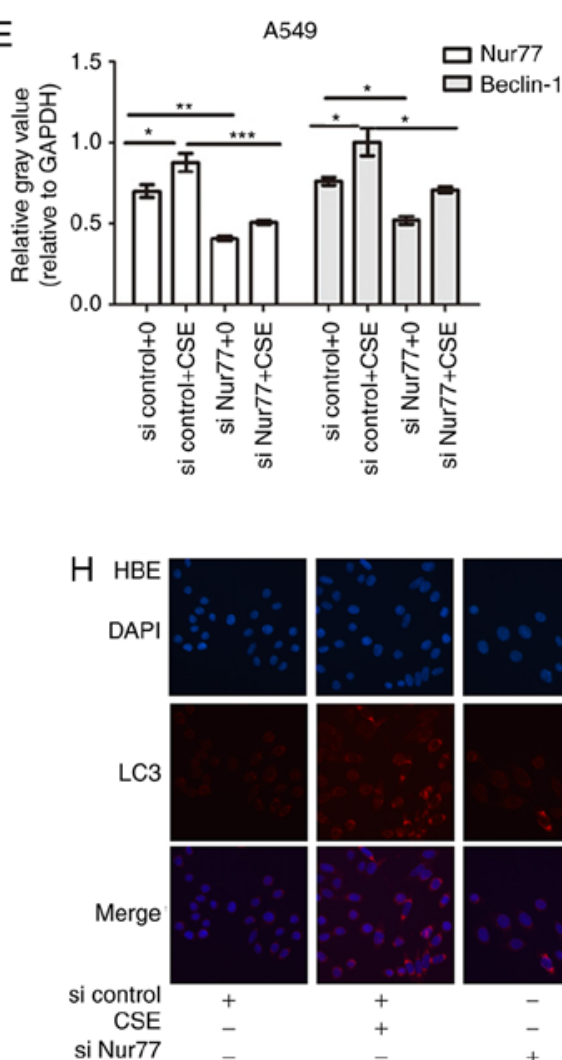
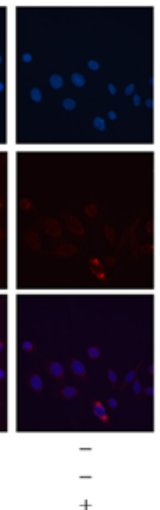

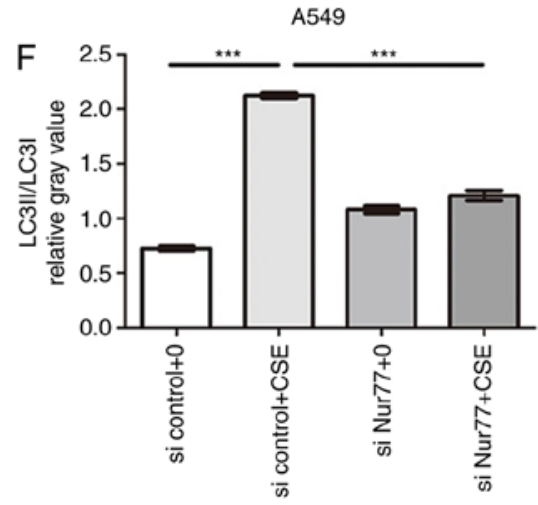

G

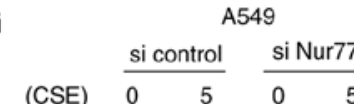

(\%)

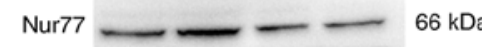

Beclin-1

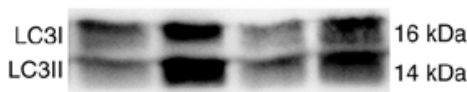

GAPDH $=37 \mathrm{kDa}$

Figure 3. Downregulation of Nur77 alleviates CSE-induced autophagy in vitro. (A) HBE or A549 cells were treated with rapamycin (1 mM) or 3-MA (2.5 mM) or left untreated and then exposed to 5\% CSE for a further $24 \mathrm{~h}$. Cell proliferation was detected by CCK-8 assay. (B-D) HBE cells were transfected with siRNA-Nur77 or control siRNA for $36 \mathrm{~h}$ in the presence or absence of $5 \% \mathrm{CSE}$ for a further $24 \mathrm{~h}$, and the cell lysates were subjected to western blot analysis using anti-Nur77, anti-Beclin-1 and anti-LC3 antibodies. (E-G) A549 cells were transfected with siRNA-Nur77 or control siRNA for $36 \mathrm{~h}$ and incubated in the presence or absence of 5\% CSE for a further $24 \mathrm{~h}$. The cell lysates were subjected to western blot analysis using anti-Nur77, anti-Beclin-1 and anti-LC3 antibodies. (H and I) Endogenous LC3 was detected via fluorescence microscopy in HBE and A549 cells transfected with siRNA-Nur77 or control siRNA for $36 \mathrm{~h}$ in the presence or absence of 5\% CSE for a further $24 \mathrm{~h}$, Scale bars, $50 \mu \mathrm{m} .{ }^{*} \mathrm{P}<0.05^{* *} \mathrm{P}<0.01$ and ${ }^{* * *} \mathrm{P}<0.001$. Each experiment was repeated at least 3 times. CSE, cigarette smoke extract; Nur77, nuclear receptor 77; HBE cells, human bronchial epithelial cells. 

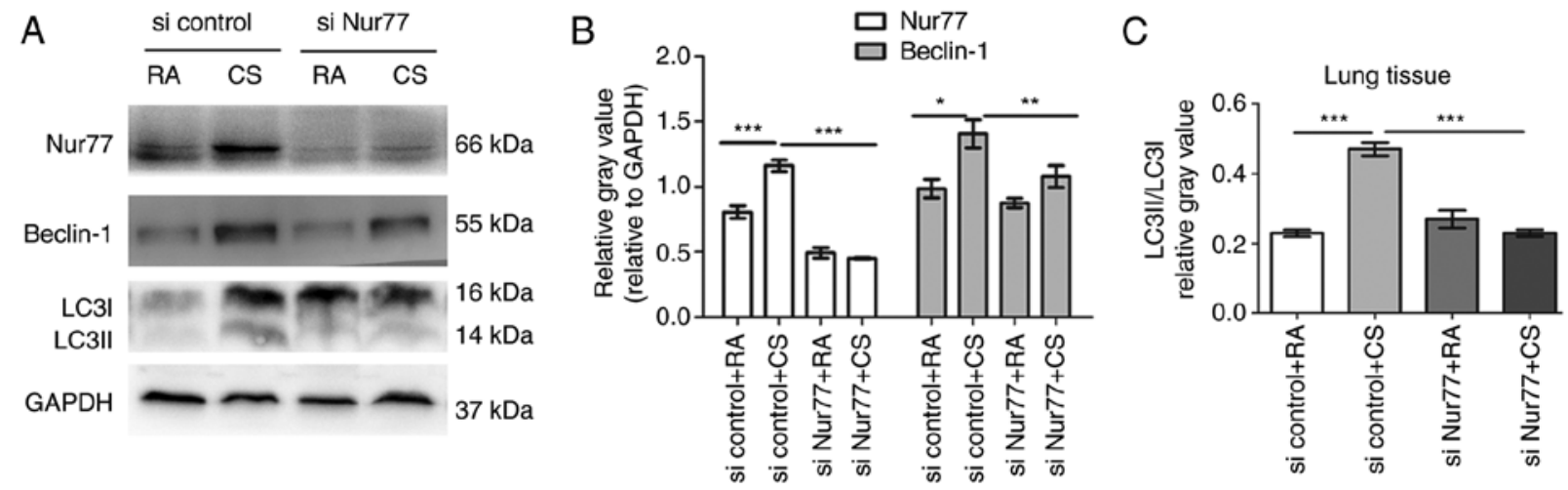

Figure 4. Downregulation of Nur77 alleviates CS-induced autophagy in vivo. (A-C) Mice were infected with siRNA-Nur77-carrying or control siRNA-carrying lentiviruses, and then exposed to RA or CS. Western blot analysis was performed to determine the protein expression of Nur77, Beclin- 1 and LC3. ${ }^{*} \mathrm{P}<0.05$ ${ }^{* *} \mathrm{P}<0.01$ and ${ }^{* * *} \mathrm{P}<0.001$. Each experiment was repeated at least 3 times. CS, cigarette smoke; RA, room air; Nur77, nuclear receptor 77; HBE cells, human bronchial epithelial cells.

A

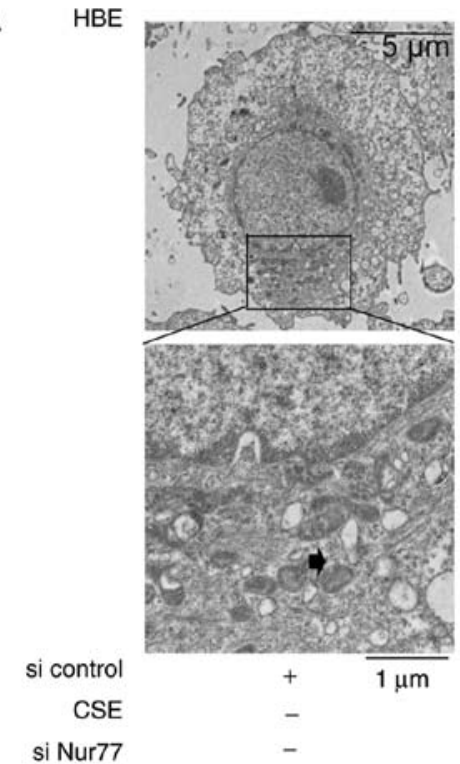

B

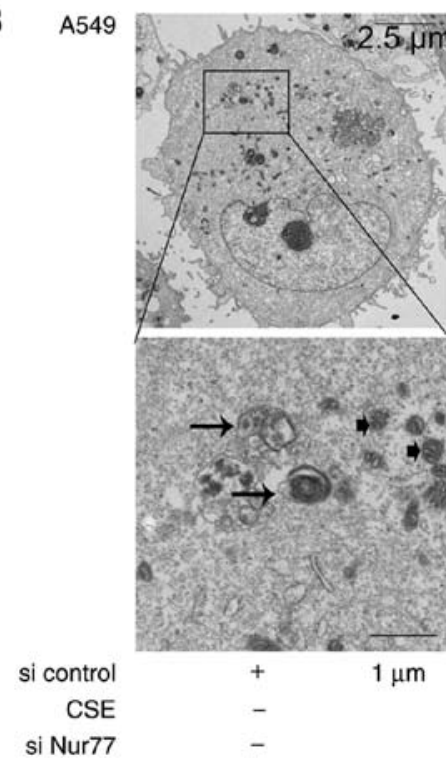

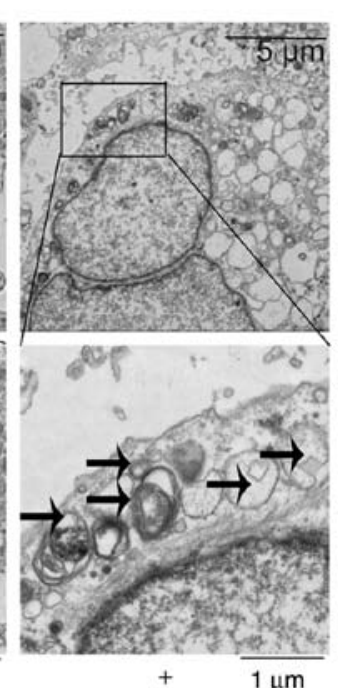
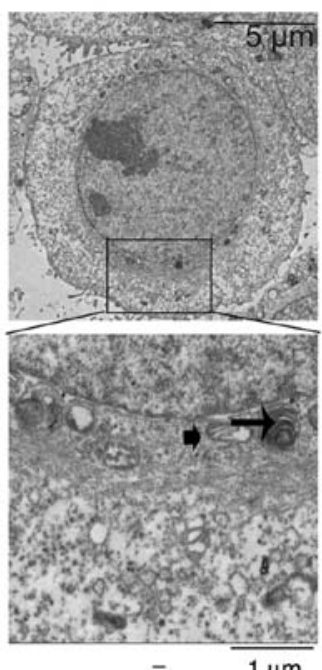

$-$

$+$
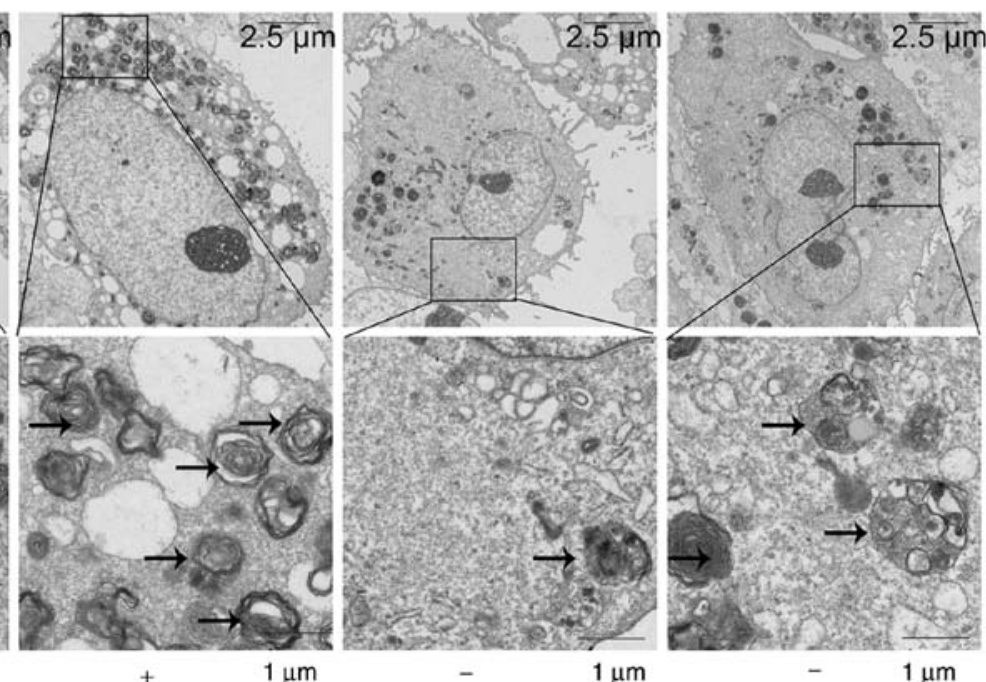

$+$

Figure 5. Knockdown of Nur77 decreases CSE-induced autophagosome formation at the ultrastructural level. (A) Transmission electron micrographs of autophagosomes in HBE cells subjected to different treatments. The long arrows indicate autophagosomes, and the short arrows indicate mitochondria. Scale bars, $5 \mu \mathrm{m}$ and $1 \mu \mathrm{m}$. (B) Transmission electron micrographs of autophagosomes in A549 cells subjected to different treatments. In (A and B), the images on the bottom panel are an enlargement of the boxed area on the top panel. The long arrows indicate autophagosomes, short arrows indicate mitochondria. Scale bars, $2.5 \mu \mathrm{m}$ and $1 \mu \mathrm{m}$. CSE, cigarette smoke extract; Nur77, nuclear receptor 77; HBE cells, human bronchial epithelial cells. 
A
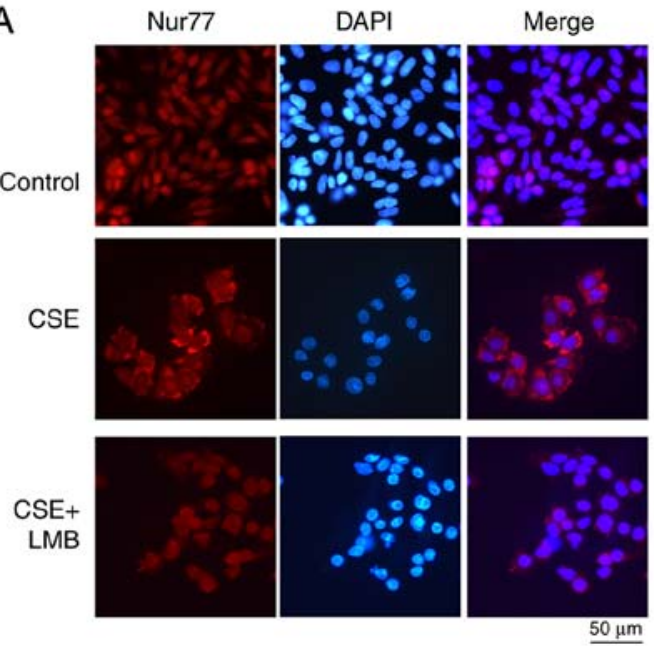

B
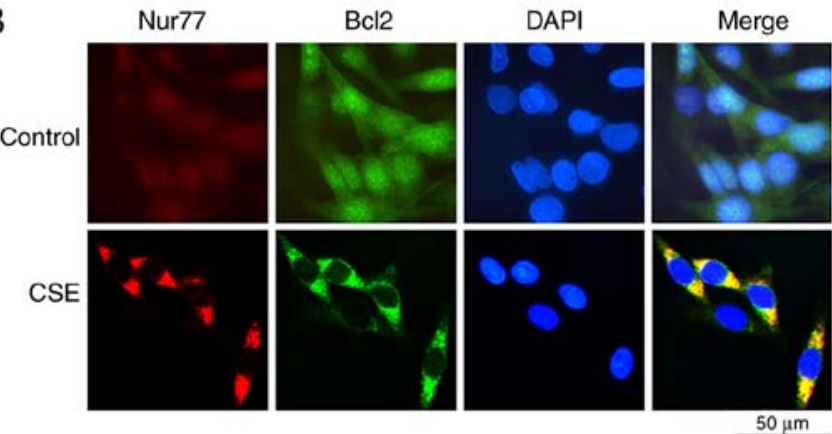

Figure 6. CSE promotes the interaction between Nur77 and Bcl2. (A) HBE cells were pre-treated with or without LMB (10 ng/ml) for $2 \mathrm{~h}$ and treated with 5\% CSE for a further $24 \mathrm{~h}$. Subsequently, Nur77 staining was examined by fluorescence microscopy. Scale bars, $50 \mu \mathrm{m}$. (B) Fluorescence microscopy was used to determine the co-localization of Nur77 and Bcl2 in HBE cells exposed to CSE for $24 \mathrm{~h}$ or left untreated. Scale bars, $50 \mu \mathrm{m}$. CSE, cigarette smoke extract; Nur77, nuclear receptor 77; HBE cells, human bronchial epithelial cells.

A

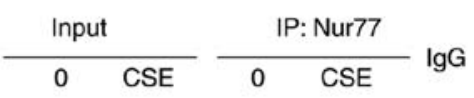

Nur77

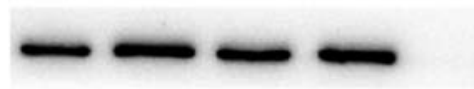

Bcl2

GAPDH

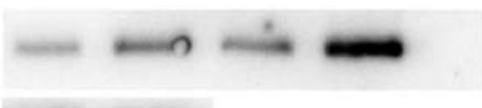

B

$\frac{\text { Input }}{0 \quad \text { CSE }} \frac{\text { IP: } B c \mid 2}{0 \quad \text { CSE }}$ IgG

$66 \mathrm{kDa}$

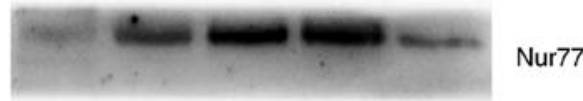

$26 \mathrm{kDa}$

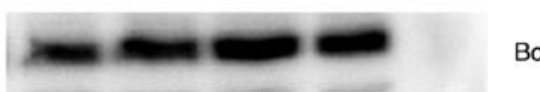

$37 \mathrm{kDa}$
Bcl2

GAPDH

Figure 7. CSE promotes the interaction between Nur77 and Bcl2. (A and B) Co-immunoprecipitation assays were used to investigate the interaction between Nur77 and Bcl 2 in HBE cells with or without CSE exposure for $24 \mathrm{~h}$. CSE, cigarette smoke extract; Nur77, nuclear receptor 77; HBE cells, human bronchial epithelial cells.

A

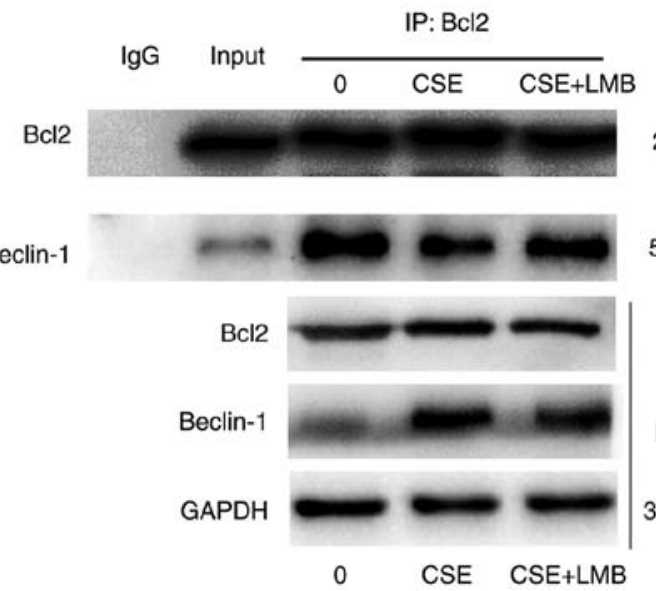

B

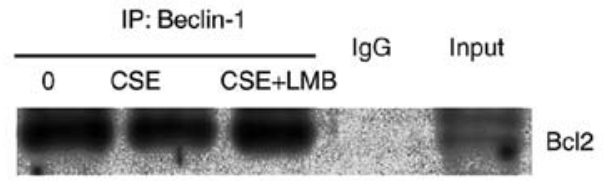

$55 \mathrm{kDa}$
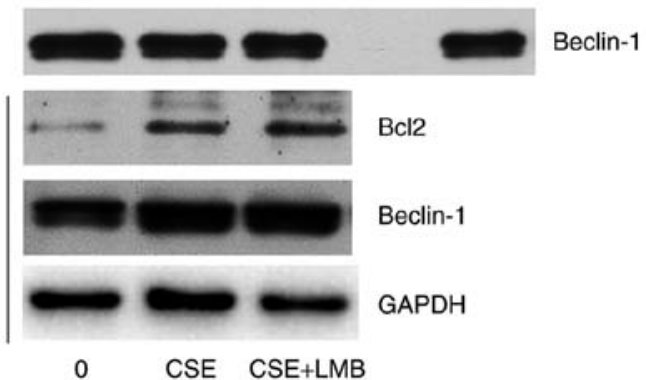

Figure 8. Nur77 plays a role in the CSE-induced dissociation of Bcl2 from Beclin-1. (A and B) Cell lysates were immunoprecipitated with anti-Bcl2 or anti-Beclin-1 antibodies, and the immunoprecipitates were detected by western blot analysis using anti-Bcl2 and anti-Beclin-1 antibodies. CSE, cigarette smoke extract; Nur77, nuclear receptor 77; HBE cells, human bronchial epithelial cells.

that the amounts of Bcl-2 and Beclin-1-pulled down by the anti-Bcl2 antibody were lower in the CSE-exposed group than in the control and LMB groups (Fig. 8). These observations confirm that CSE induces the interaction between Nur77 and Bcl-2, which leads to the dissociation of Bcl-2 from Beclin-1.

\section{Discussion}

COPD is characterized by progressive, partially reversible airflow obstruction, and its pathologic features include chronic bronchitis, airway remodeling and emphysema (3). 
Cigarette smoking is the strongest risk factor for $\operatorname{COPD}(2,31)$. Autophagy plays a detrimental role in CS-induced COPD by damaging lung epithelial cells (6). However, the mechanisms through which CS triggers autophagy remain unclear. In this study, we explored the role of Nur77 in CS-induced autophagy and demonstrated that CS induced Nur77 expression and nuclear export, and then promoted the interaction between Nur77 and Bcl2, which dissociated Bcl2 from Beclin-1 and consequently activated autophagy.

The orphan nuclear receptor Nur77 serves mainly as a transcription factor to regulate the expression of multiple genes in the nucleus. Nur77 also translocates from the nucleus to the cytoplasm to exert biological effects. Nur77 exerts critical effects on inflammation, and on the proliferation, differentiation and apoptosis of cancer cells (32-35). There is evidence to indicate that Nur77 can act as a therapeutic target to induce cell death in various types of cancer, such as lymphoma and melanoma, in which Nur77 is downregulated $(19,36)$. Several studies have also explored the significance of Nur77-mediated cell survival in breast cancer, pancreatic tumors and lung cancer, in which Nur77 is upregulated (37-39). Nur77 also has dual effects in non-tumoral diseases. For example, Nur77 can inhibit PASMC proliferation through the inhibition of the Axin2- $\beta$-catenin signaling pathway, exerting a protective function against hypoxic pulmonary hypertension (11). Nur77 may be a molecular target for the prevention of sepsis, as it interacts with TRAF6 and regulates its autoubiquitination (13). However, the expression of Nur77 family genes is induced by cadmium exposure, which leads to lung cell death, and may thus cause pulmonary toxicity (40). Nicotine, an ingredient found in tobacco, induces Nur77 expression in human lung cancer cells (41). Accumulating evidence suggests that Nur77 is widely expressed in the lungs, although the nature of the expression and function of Nur77 in CS-induced COPD remains unclear. In the present study, we observed that Nur77 expression was upregulated following exposure to CSE in a concentration-dependent manner in pulmonary epithelial cells and that CSE accelerated HBE and A549 cell death, while siRNA-Nur77 partially alleviated this effect.

Autophagy is an evolutionarily conserved catabolic pathway that delivers long-lived proteins and damaged organelles to lysosomes for degradation (42). Moderate autophagy facilitates the maintenance of cellular homeostasis, although excessive autophagy leads to cell death $(43,44)$. For example, in CS-induced COPD, augmented autophagy has been reported to promote CS-induced pulmonary emphysema and to regulate the secretion and senescence of airway epithelial cells (42-44). Nur77 can interact with p53 to promote autophagic cell death, which is involved in regulating gene expression in the nucleus (29). It has also been demonstrated that Nur77 is translocated to the cytoplasm and targets the mitochondria, dissipating the mitochondrial membrane potential and inducing the autophagy pathway to ultimately lead to malignant melanoma cell death (19). Dendrogenin A (DDA), a natural metabolite of cholesterol and histamine, induces Nur77-dependent lethal autophagy in melanoma and acute myeloid leukemia (36). In this study, we discovered that Nur77 plays an important role in CSE-induced autophagy and promotes cell death by autophagy. The increased conversion of LC3II to LC3I was accompanied by Nur77 overexpres- sion in the HBE and A549 cells exposed to CSE. We further investigated the association between Nur77 and CSE-induced autophagy by knocking down Nur77 with siRNA. The knockdown of Nur77 impaired CSE-induced autophagy, confirming that the functional induction of autophagy by CSE is partly dependent on Nur77.

Pro-apoptotic and anti-apoptotic Bcl-2 family proteins share a motif known as the Bcl-2 homology 3 (BH3) motif, which is involved in regulating apoptosis $(22,30)$. Nur77, through its LBD, binds adjacent to the $\mathrm{BH} 3$ peptide-binding crevice of Bcl-2 family proteins and converts anti-apoptotic proteins to pro-apoptotic proteins $(22,23,30)$. The autophagy-related protein, Beclin-1, binds to the BH3-binding pocket on anti-apoptotic Bcl-2 family proteins though its BH3-like domain, which inhibits autophagy $(24,45)$. The dissociation of $\mathrm{Bcl} 2$ from Beclin-1 has been verified to trigger autophagy $(45,46)$. The interaction between Nur77 and Bcl2 family proteins is known to be associated with autophagy and cell death regulation. We thus hypothesized that the Nur77-Bcl 2 complex dissociates Beclin-1 from Bcl2 to mediate CSE-induced autophagy. In this study, we found that CSE increased Nur77-Bcl2 interactions from the control levels. We also observed that CSE induced the dissociation of Beclin-1 from Bcl2, enhancing autophagy. The limitation of Nur77 nuclear export re-stabilized the Bcl2-Beclin-1 heterodimer.

In conclusion, the data from this study support the hypothesis that Nur77 is overexpressed in pulmonary tissue and in HBE and A549 cells exposed to CS, and that Nur77 promotes autophagy by binding to $\mathrm{Bcl} 2$ and weakening the affinity of Beclin-1 for Bcl2. These results may provide novel insight into the pathogenesis of COPD and may into the mechanisms underlying CSE-induced COPD. Our data may also aid in the development of novel treatment strategies for COPD.

\section{Acknowledgements}

Not applicable.

\section{Funding}

The present study was supported in part by the National Natural Science Foundation of China (grant no. 81660008).

\section{Availability of data and materials}

The datasets used during the present study are available from the corresponding author on reasonable request.

\section{Authors' contributions}

HQ participated in the experimental design, completed the animal experiments and the cell experiments, performed the data analysis, and drafted and edited the manuscript. FG and YW assisted with the animal experiments and drafted the manuscript. BH contributed to the immunofluorescence assay and the immunoassays. LP carried out the electron microscopy analysis. BM performed the data analysis and statistical analysis. CW designed the experiments, drafted and edited the manuscript, and supervised the completion of the experiment. All authors have read and approved the final manuscript. 


\section{Ethics approval and consent to participate}

All the animal experiments were approved by the Central South University Animal Care Committee.

\section{Patient consent for publication}

Not applicable.

\section{Competing interests}

The authors declare that they have no competing interests.

\section{References}

1. Vogelmeier CF, Criner GJ, Martinez FJ, Anzueto A, Barnes PJ, Bourbeau J, Celli BR, Chen R, Decramer M, Fabbri LM, et al: Global strategy for the diagnosis, management and prevention of chronic obstructive lung disease 2017 Report: GOLD executive summary. Respirology 22: 575-601, 2017.

2. Rosenberg SR, Kalhan R and Mannino DM: Epidemiology of chronic obstructive pulmonary disease: Prevalence, morbidity, mortality, and risk factors. Semin Respir Crit Care Med 36: 457-469, 2015.

3. Bagdonas E, Raudoniute J, Bruzauskaite I and Aldonyte R: Novel aspects of pathogenesis and regeneration mechanisms in COPD. Int J Chron Obstruct Pulmon Dis 10: 995-1013, 2015.

4. He Y, Jiang B, Li LS, Li LS, Ko L, Wu L, Sun DL, He SF, Liang BQ, Hu FB and Lam TH: Secondhand smoke exposure predicted COPD and other tobacco-related mortality in a 17-year cohort study in China. Chest 142: 909-918, 2012.

5. Chen Z, Peto R, Zhou M, Iona A, Smith M, Yang L, Guo Y, Chen Y, Bian Z, Lancaster G, et al: Contrasting male and female trends in tobacco-attributed mortality in China: Evidence from successive nationwide prospective cohort studies. Lancet 386 : 1447-1456, 2015.

6. Vij N, Chandramani-Shivalingappa P, Van Westphal C, Hole R and Bodas M: Cigarette smoke-induced autophagy impairment accelerates lung aging, COPD-emphysema exacerbations and pathogenesis. Am J Physiol Cell Physiol 314: C73-C87, 2018.

7. Pawlak A, Strzadala L and Kalas W: Non-genomic effects of the NR4A1/Nur77/TR3/NGFIB orphan nuclear receptor. Steroids 95: 1-6, 2015

8. Wang Z, Benoit G, Liu J, Prasad S, Aarnisalo P, Liu X, Xu H, Walker NP and Perlmann T: Structure and function of Nurr1 identifies a class of ligand-independent nuclear receptors. Nature 423: 555-560, 2003.

9. Kurakula K, Koenis DS, van Tiel CM and de Vries CJ: NR4A nuclear receptors are orphans but not lonesome. Biochim Biophys Acta 1843: 2543-2555, 2014.

10. Niu G, Lu L, Gan J, Zhang D, Liu J and Huang G: Dual roles of orphan nuclear receptor TR3/Nur77/NGFI-B in mediating cell survival and apoptosis. Int Rev Cell Mol Biol 313: 219-258, 2014.

11. Nie X, Tan J, Dai Y, Mao W, Chen Y, Qin G, Li G, Shen C, Zhao J and Chen J: Nur77 downregulation triggers pulmonary artery smooth muscle cell proliferation and migration in mice with hypoxic pulmonary hypertension via the Axin2- $\beta$-catenin signaling pathway. Vascul Pharmacol 87: 230-241, 2016.

12. Kurakula K, Vos M, Logiantara A, Roelofs JJ, Nieuwenhuis MA, Koppelman GH, Postma DS, van Rijt LS and de Vries CJ: Nuclear receptor Nur77 attenuates airway inflammation in mice by suppressing NF- $\mathrm{B}$ activity in lung epithelial cells. J Immunol 195: 1388-1398, 2015.

13. Li XM, Zhang S, He XS, Guo PD, Lu XX, Wang JR, Li JM and $\mathrm{Wu} \mathrm{H}$ : Nur77-mediated TRAF6 signalling protects against LPS-induced sepsis in mice. J Inflamm (Lond) 13: 4, 2016.

14. Mizumura K, Cloonan S, Choi ME, Hashimoto S, Nakahira K, Ryter SW and Choi AM: Autophagy: Friend or foe in lung disease? Ann Am Thorac Soc 13 (Suppl 1): S40-S47, 2016.

15. Haspel JA and Choi AM: Autophagy: A core cellular process with emerging links to pulmonary disease. Am J Respir Crit Care Med 184: 1237-1246, 2011.

16. Araya J, Hara H and Kuwano K: Autophagy in the pathogenesis of pulmonary disease. Intern Med 52: 2295-2303, 2013.
17. Lam HC, Cloonan SM, Bhashyam AR, Haspel JA, Singh A, Sathirapongsasuti JF, Cervo M, Yao H, Chung AL, Mizumura K, et al: Histone deacetylase 6-mediated selective autophagy regulates COPD-associated cilia dysfunction. J Clin Invest 123: 5212-5230, 2013.

18. Dickinson JD, Alevy Y, Malvin NP, Patel KK, Gunsten SP, Holtzman MJ, Stappenbeck TS and Brody SL: IL13 activates autophagy to regulate secretion in airway epithelial cells. Autophagy 12: 397-409, 2016.

19. Wang WJ, Wang Y, Chen HZ, Xing YZ, Li FW, Zhang Q, Zhou B, Zhang HK, Zhang J, Bian XL, et al: Orphan nuclear receptor TR3 acts in autophagic cell death via mitochondrial signaling pathway. Nat Chem Biol 10: 133-140, 2014.

20. Gao H, Chen Z, Fu Y, Yang X, Weng R, Wang R, Lu J, Pan M, Jin K, McElroy C, et al: Nur77 exacerbates PC12 cellular injury in vitro by aggravating mitochondrial impairment and endoplasmic reticulum stress. Sci Rep 6: 34403, 2016.

21. Liang B, Song X, Liu G, Li R, Xie J, Xiao L, Du M, Zhang Q, $\mathrm{Xu} \mathrm{X}$, Gan X and Huang D: Involvement of TR3/Nur77 translocation to the endoplasmic reticulum in ER stress-induced apoptosis. Exp Cell Res 313: 2833-2844, 2007.

22. Thompson J and Winoto A: During negative selection, Nur77 family proteins translocate to mitochondria where they associate with Bcl-2 and expose its proapoptotic BH3 domain. J Exp Med 205: 1029-1036, 2008

23. Godoi PH, Wilkie-Grantham RP,Hishiki A, Sano R,Matsuzawa Y, Yanagi H, Munte CE, Chen Y, Yao Y, Marassi FM, et al: Orphan nuclear receptor NR4A1 Binds a novel protein interaction site on anti-apoptotic B cell lymphoma gene 2 family proteins. J Biol Chem 291: 14072-14084, 2016.

24. Robert G, Gastaldi C,Puissant A, Hamouda A, Jacquel A, Dufies M, Belhacene N, Colosetti P, Reed JC, Auberger P and Luciano F: The anti-apoptotic Bcl-B protein inhibits BECN1-dependent autophagic cell death. Autophagy 8: 637-649, 2012.

25. Levine B, Sinha SC and Kroemer G: Bcl-2 family members: Dual regulators of apoptosis and autophagy. Autophagy 4: 600-606, 2008.

26. D'Hulst AI, Vermaelen KY, Brusselle GG, Joos GF and Pauwels RA: Time course of cigarette smoke-induced pulmonary inflammation in mice. Eur Respir J 26: 204-213, 2005.

27. Crowe CR, Chen K, Pociask DA, Alcorn JF, Krivich C, Enelow RI, Ross TM, Witztum JL and Kolls JK: Critical role of IL-17RA in immunopathology of influenza infection. J Immunol 183: 5301-5310, 2009

28. Hodge S, Hodge G, Ahern J, Jersmann H, Holmes M and Reynolds PN: Smoking alters alveolar macrophage recognition and phagocytic ability: Implications in chronic obstructive pulmonary disease. Am J Respir Cell Mol Biol 37: 748-755, 2007.

29. Bouzas-Rodríguez J, Zárraga-Granados G, Del Rayo Sánchez-Carbente M, Rodríguez-Valentín R, Gracida X, Anell-Rendón D, Poksay KS, Madden DT, Covarrubias L and Castro-Obregón S: Correction: The nuclear receptor NR4A1 induces a form of cell death dependent on autophagy in mammalian cells. PLoS One 10: e0118718, 2015.

30. Lin B, Kolluri SK, Lin F, Liu W, Han YH, Cao X, Dawson MI, Reed JC and Zhang XK: Conversion of Bcl-2 from protector to killer by interaction with nuclear orphan receptor Nur77/TR3. Cell 116: 527-540, 2004

31. Allinson JP, Hardy R, Donaldson GC, Shaheen SO, Kuh D and Wedzicha JA: Combined impact of smoking and early-life exposures on adult lung function trajectories. Am J Respir Crit Care Med 196: 1021-1030, 2017.

32. Hu M, Luo Q, Alitongbieke G, Chong S, Xu C, Xie L, Chen X, Zhang D, Zhou Y, Wang Z, et al: Celastrol-induced Nur77 interaction with TRAF2 alleviates inflammation by promoting mitochondrial ubiquitination and autophagy. Mol Cell 66: 141-153 .e6, 2017.

33. Hamers AA, Uleman S, van Tiel CM, Kruijswijk D, van Stalborch AM, Huveneers S, de Vries CJ and van 't Veer C: Limited role of nuclear receptor Nur77 in Escherichia coli-induced peritonitis. Infect Immun 82: 253-264, 2014.

34. Myers DR, Lau T, Markegard E, Lim HW, Kasler H, Zhu M, Barczak A, Huizar JP, Zikherman J, Erle DJ, et al: Tonic LAT-HDAC7 signals sustain Nur77 and Irf4 expression to tune naive CD4 T cells. Cell Rep 19: 1558-1571, 2017.

35. Yu C, Cui S, Zong C, Gao W, Xu T, Gao P, Chen J, Qin D, Guan Q, Liu Y, et al: The orphan nuclear receptor NR4A1 protects pancreatic $\beta$-cells from endoplasmic reticulum (ER) stress-mediated apoptosis. J Biol Chem 290: 20687-20699, 2015.

36. Segala G, David M, de Medina P, Poirot MC, Serhan N, Vergez F, Mougel A, Saland E, Carayon K, Leignadier J, et al: Dendrogenin A drives LXR to trigger lethal autophagy in cancers. Nat Commun 8: 1903, 2017. 
37. Hedrick E, Lee SO, Doddapaneni R, Singh M and Safe S: Nuclear receptor 4A1 as a drug target for breast cancer chemotherapy. Endocr Relat Cancer 22: 831-840, 2015.

38. Lee SO, Jin UH, Kang JH, Kim SB, Guthrie AS, Sreevalsan S, Lee JS and Safe S: The orphan nuclear receptor NR4A1 (Nur77) regulates oxidative and endoplasmic reticulum stress in pancreatic cancer cells. Mol Cancer Res 12: 527-538, 2014.

39. Lee SO, Andey T, Jin UH, Kim K, Singh M and Safe S: The nuclear receptor TR3 regulates mTORC1 signaling in lung cancer cells expressing wild-type p53. Oncogene 31: 3265-3276, 2012.

40. Shin HJ, Lee BH, Yeo MG, Oh SH, Park JD, Park KK, Chung JH, Moon CK and Lee MO: Induction of orphan nuclear receptor Nur77 gene expression and its role in cadmium-induced apoptosis in lung. Carcinogenesis 25: 1467-1475, 2004.

41. Chen GQ, Lin B, Dawson MI and Zhang XK: Nicotine modulates the effects of retinoids on growth inhibition and RAR beta expression in lung cancer cells. Int J Cancer 99: 171-178, 2002.

42. Chen ZH, Kim HP, Sciurba FC, Lee SJ, Feghali-Bostwick C, Stolz DB, Dhir R,Landreneau RJ, Schuchert MJ, Yousem SA, et al: Egr-1 regulates autophagy in cigarette smoke-induced chronic obstructive pulmonary disease. PLoS One 3: e3316, 2008.

43. Wang G, Zhou H, Strulovici-Barel Y, Al-Hijji M, Ou X, Salit J, Walters MS, Staudt MR, Kaner RJ and Crystal RG: Role of OSGIN1 in mediating smoking-induced autophagy in the human airway epithelium. Autophagy 13: 1205-1220, 2017.
44. Li Y, Yu G, Yuan S, Tan C, Xie J, Ding Y, Lian P, Fu L, Hou Q, $\mathrm{Xu}$ B and Wang H: 14,15-Epoxyeicosatrienoic acid suppresses cigarette smoke condensate-induced inflammation in lung epithelial cells by inhibiting autophagy. Am J Physiol Lung Cell Mol Physiol 311: L970-L980, 2016.

45. Wei Y,Pattingre S,SinhaS,BassikM andLevine B:JNK1-mediated phosphorylation of Bcl-2 regulates starvation-induced autophagy. Mol Cell 30: 678-688, 2008.

46. Liu J, Liu W, Lu Y, Tian H, Duan C, Lu L, Gao G, Wu X, Wang $X$ and Yang H: Piperlongumine restores the balance of autophagy and apoptosis by increasing BCL2 phosphorylation in rotenone-induced Parkinson disease models. Autophagy 14: 845-861, 2018.

(7) (9) This work is licensed under a Creative Commons Attribution-NonCommercial 4.0 International (CC BY-NC 4.0) License. 